\title{
Methodological problems of the social sciences. Misunderstandings and clarifications
}

\begin{abstract}
A. Fusari
ABSTRACT

Growing technological changes and innovation make it increasingly difficult to understand the course of social reality, while the intensification of the relations between different regions of the Earth and the power achieved by financial capital on a world scale amplify the dimensions and visibility of disequilibria and iniquities, and sharpen frustration and sentiments of insecurity. The roots of this theoretical and practical confusion are identified, in our paper for submission, with the adoption within the social sciences of the method of observation and verification. This may seem surprising in the light of the fact that the triumph of this method facilitated the emergence of the modern natural (and mechanical) sciences. And in fact, just this success has propelled the extension of the observation-verification method into the social sciences, where it is today dominant. The deficiencies of this method in the analysis of social reality are, however, masked by the trappings of scientific rigour imparted, which is often enhanced by additional borrowing of method from the mathematical and formal sciences. It must be recognized that the observationverification works well when applied to quasi-stationary societies, where the key hypothesis of the repetitiveness (or quasi-repetitiveness) of events typical of the natural sciences and the corresponding method is fulfilled. But with the advent of modern dynamic society, itself very much an effect of the great advancement of the natural and formal sciences, the failure of the methodologies of these sciences with regard to the analysis of social reality has become increasingly marked and its consequences ever more devastating. My book Methodological Misconceptions in the Social Sciences, Springer 2014, was dedicated to an accurate analysis of this embarrassing situation and a consideration of ways to remedy it. The most efficacious way to meet this fleeting social reality seems to be to scientifically highlight basic institutions, economic behaviour and values with their steady changes caused by the accumulation of creative and choice processes. In doing so, long-run trends can be explored in order to understand and manage the disequilibrating-reequilibrating motion characterizing the life of dynamic societies.
\end{abstract}

\section{INTRODUCTION}

This paper sets out a short synthesis of my book, Methodological Misconceptions in the Social Sciences: Rethinking social thought and social processes (Springer 2014). The synthesis is written in a mode understandable also to students with little knowledge on method. However, students unhappy with the operational simplifications in this paper may use it as an introduction on method and hence proceed to the book itself. Some other books of mine can increase such deeper understanding, in particular A New Economics for Modern Dynamic Economies (Routledge 2017), which is full of mathematical formalizations and treats the question of method with reference to the economy. Some other consideration on method are also drawn in my booklet Understanding the Course of Social Reality (Springer 2016), and in two nearly completed books dedicated to the problem of power and ethics, two important aspects of social life afflicted by great ambiguities and forms of oppression.

We witness today a curious and intriguing intellectual situation regarding the method of social thought, one quite opposite to that characterizing the natural sciences. These latter, having made a promising start on method through Archimedes' investigation based on experiments, stagnated for over 1500 years before Galileo's elaborations allowed a real explosion of 
scientific knowledge. But what happened to social thinking? The deepening on method has for a long time inspired, mainly due to the philosophical hegemony of the Christian Church, a vision appropriate to the investigation of human societies based on the idea of organization. This idea was mainly referred to the study of nature. But later it was replaced by those elaborations on method mainly due to Galileo and based on the accurate observation of reality. In fact, this new vision had started to be very successful and, in consequence, it conquered also social studies, to which it has proved to be inappropriate, as we shall see.

This essay will consider a situation going in the opposite direction that that which we witness in the sixteenth and seventeenth centuries. In those centuries, the organizational vision of the Medieval Church was abandoned and the development of science started to be based on the method of observation and experimentation. We shall see that, to overcome the obstacles that the adoption of the observation perspective caused to social thought, it needs to return to the medieval organizational vision, which has been obscured and eclipsed by the great success known by the observational method in the natural sciences. In other words, we shall see that social thought needs to come back to medieval thinking, just the opposite of what happened five centuries ago in the study of natural events that returned to Archimedes' teaching.

The clarifications on method that follow may be also considered useful in saving the contemporary world from the mortal kiss of an irreversible ecological crisis.

The question of method has known two main developments, both rich in explanatory capacity: the method that can be denominated of 'abstract rationality', concerning logic-formal and mathematical sciences and based on very abstract and general postulates from which some teachings distinguished by high generality can be deduced; and the observational-experimental method, which takes pains to practice a strict adherence to the analyzed reality and which heeds the substantial repetitiveness of the reality to which it is referred as a condition for observation to provide reliable teachings. Neither of the two methods above can be referred to social reality, both because (differently from logic-formal sciences) in this case it is not possible to abstract from the observed reality, and because it is impossible to use the observationalexperimental method as social reality does not fulfill the requisite of repetitiveness necessary for extracting teachings from observations. Nevertheless, studies on social reality use the two methods considered above, or some combination. Their evident non-functioning in the presence of the growing social change typical of modern societies has pushed students to specify a multiplicity of interpretative hypotheses that cause indeterminacy, inconsistencies, limitations and interpretative confusion forbidding the cumulativeness of results and hence the scientific content of knowledge.

This methodological fragmentation causes insolvable conflicts and misunderstandings and cannot be accepted. It is urgent that we pursue the definition of a third method, appropriate to investigate social reality even if this is non-repetitive because a product of the organizational action of man. It seems, therefore, that such a new method must be based on an organizational vision, that is, on the definition of rules able to warrant a rational and efficient interpretation and administration of a non-repetitive reality. A main lack in the present world is the inexistence of such a method, an absence that undermines the scientific character of social thought. This essay will attempt to define such a method, essential if social thought is to be taken outside the present intolerable confusion.

The essay begins by pointing out the pointless of the great theories on method, that is, the abstract rationality and the observation-experimentation ones, to describe and understand social reality. Then we consider the multiplicity of alternative hypotheses and methodologies 
that have been directed to remedy the difficulties of the above two methods in treating social phenomena. Soon after, we set out an interpretation that bases the method of inquiry on social reality on a model privileging the organizational side. We pay attention to the classification and interaction of basic and particularly meaningful aspects of social reality, as well as on the methodological distinction between the organizational 'necessity' of social systems (that is, required by reasons of organizational rationality and efficiency) and 'choice-possibility' as centered on the civilization options and choices. This will allow the defining of an interpretative model based on the action of man as builder and organizer of social systems, an interpretation able to understand the main vicissitudes of those systems. We shall consider the deceits that the Roman Church derived from her renunciation of the medieval organizational vision, under the suggestion of the successes gained by the observational-experimental method in the study of natural reality. We shall also consider the effects of the misunderstandings above, mainly in the field of ethics, and make clear that those misunderstandings are increasingly damaging the ecumenical action of the Christian Church in the global society. Finally, we shall dedicate some attention to the theory of social and historical processes. ${ }^{1}$

\section{THREE GREAT CLASSIFICATIONS CONCERNING THEORIES ON METHOD}

What about the situation in our time? Method is in a condition in some sense hybrid. Some questions pertaining to method are currently treated with great severity and in some sophisticated ways, while others stagnate in a condition of great confusion, appearances notwithstanding, sometimes mixed with an apparent severity that makes the confusion almost indecipherable.

It is opportune to distinguish the current method and philosophy of sciences in three courses, starting from the first born in forms able to stimulate fecund and rigorous teachings. More precisely, we start with the most abstract and ancient of them, concerning mathematics and logic-formal sciences. This method is based on what may be called 'abstract rationality' criterion, consisting in the deduction of logical implications from postulates largely abstracted from factual reality. Such a high degree of abstraction allows explanations characterized by a high degree of generality, sometimes able to offer unexpected solutions as do, for instance, Boolean algebra and non-Euclidean geometries that derive from logical abstractions apparently almost unreal, but which have shown in due time precious in facilitating calculations, in astronomic exploration and the formulation of general theories such as Einstein's theory of relativity. Euclidean geometry is the most relevant application of this method.

The analysis of more specific aspects of reality has experienced for a long time a substantial methodological fragility, mainly in the interpretation of the natural world and interaction with it. In fact, the method of the natural sciences has remained for a long time in an equivocal condition, often having known an embarrassing retrocession with respect to Archimedes' contributions based on experimentation.

Precisely, knowledge of the natural world was obstructed for a long time by the habit of basing research on premises that abstracted from the observation of factual evidence. An example: Aristoteles explained the disappearance of some birds in winter with the hypothesis that they went into hibernation in the bowels of the Earth. Such an explanation was accepted for almost

${ }^{1}$ A useful treatment of the above themes is A. Fusari, Contribution to the debate on cultural relativism and absolutism, Sociologia, year XL, n $1,2007$. 
1500 years, until the emperor Fredrich the second of Hohenstaufen, who understood through accurate observations that the disappearance of some birds was due to their migration to hotter countries. But notwithstanding such evidence on the importance of observation to understanding natural phenomena, in some other centuries observation and experimentation was put aside by official science. The opposition of the Church to Galileo is often attributed to biblical citations such as Joshua's command to the sun to stop. In effect, the Ptolemaic representation of the geocentric solar system implied a substantial privilege of the Earth, located at the centre of Universe by the Creator. In consequence of this explanatory reference to God's will, the heliocentric theory formulated by Aristarchus of Samos was put aside.

The debate on universals, centered on the opposition between nominalism and realism, that is, whether definitions were nominal or real, characterized the discussion on method for a long time. The domination of Aristotelian-Ptolemaic thinking pushed theoretical meditation on a road attractive and rich in culture and in reference to the role of reason; yet a road completely in the wrong direction with regard to the analysis of the natural world as centered on the idea that the role of natural science is to penetrate the reason why God has created the world such as it is. True enough, a disregarded number of irregular and heterodox students, such as alchemists and magicians, trusted in the importance of experiments, even if sometimes with senseless purposes - for instance, the search to discover the philosophers' stone. In the end, Francis Bacon and even more Galileo Galilei clarifed the inappropriateness of the organizational medieval criterion based on the understanding of the reason behind the organizational forms established by God for the natural world. Such a vision of nature as directed to the understanding of the impenetrable will of God, which in fact each religion represents differently from others, was replaced by the observation-experimental method anticipated by Archimedes, which bases the study of natural phenomena on the cooperation of mathematics and observation, mainly through mathematical models directed to express laws of motion of nature, and submitted to verification through accurate observations and experiments on the phenomena in question.

The observational-experimental method is based on the hypothesis of repetitiveness of the considered phenomena: a hypothesis largely reflected by the natural world, except in the case of catastrophic events. Such a hypothesis substantially operates in primitive (quasi-stationary) societies and also with regard to natural phenomena that know mutations in very long periods of time, for instance the Darwinian apparition of new species over millennia.

However, the idea of repetitiveness can be referred to a very low number of social phenomena. Therefore, our analysis needs to be extended to an excluded middle, that is, the definition of a method that is appropriate to social thinking.

\section{The methodological drama of social thought; strong and feeble organizational method. The incommensurabilism of the heterodox}

The references to natural laws expressed by Thomas Aquinas' teaching that can be considered precursors of the modern doctrine of natural law were deprived of fecundity for the study of social reality by the sharp insistence of this author on the role of reason. In fact, the very idea of basing the building of social thought on supposed natural laws is contradicted by the fact that the contents of social systems depend on man's constructional and creative action. In effect, such an idea is contradicted by the great variety of human society that anthropology makes well evident. The above degeneracy of jusnaturalist flavor has favored the extension of the observational method to the study of social reality.

The treatment of the method of social thought, which is the objective of this essay, can 
therefore usefully start from the exploration of the degree of reliability of the observationalexperimental method in the study of social reality. Such an exploration may be centered on the distinction between 'strong observationism' and 'feeble observationism'. Strong observationism takes as its hypothesis the 'repetitiveness' and 'acceptance' of existing and observed reality. The formalization of such a method can be expressed: $\mathrm{O}-\mathrm{H}-\mathrm{O}_{\mathrm{c}}$ : from the observation $\mathrm{O}$ is deduced an explanatory hypothesis $\mathrm{H}$; it will follow the verification $\mathrm{O}_{\mathrm{c}}$ of the results provided by the theoretical model $\mathrm{H}$; the formulated theory will be accepted or rejected if it reproduces or not the considered phenomena. Karl Popper has proposed a more intransigent formalization, which eliminates the first term 0 in the above expression and opposes the acceptance of the hypothesized theory even in case it is contradicted by only one experiment. Clearly, both methodologies are based on the two hypotheses of repetitiveness of observed phenomena and acceptance of factual reality. In fact, even if the principle of falsification proposes a very severe criterion of verification, it is nonetheless based on experimental verification that, as such, implies the idea of repetitiveness and acceptance of the observed reality. But social change implies that the falsifying event is not a remote possibility in the motion of social reality - it is always around the corner. ${ }^{2}$

The most careful social students soon started to have serious doubts about the use of the observational-experimental method, and those doubts have promoted a growing variety of proposals on method. Pareto's inquiry is a primary example of such methodological pluralism. This author bases his model of general economic equilibrium on the method of abstract rationality. But his sociological thinking strictly considers the content of human behaviour; in consequence, he rejects the deductive method, this being denied by men's instincts and irrational behaviour. Therefore, Pareto suggests the pseudo rational method of residuals and derivatons. ${ }^{3}$ But this forgets that man is forced to act rationally by the competition of rivals; so that instincts and ignorance can only cause occasional deviations from rational behavior. We see, therefore, that this important author jumps from an extreme rationalism in economics to renouncing the postulate of rationality in sociology. Moreover, Pareto also uses the observational-experimental method, for example in his analysis of alfa coefficient concerning income distribution.

The great success of the Galilean observational-experimental method caused the extension of this method to other realities, including the social one. But under an adjustment: to the idea of strong observationism, that is, for the condition of repetitiveness of phenomena and the acceptance of existence was substituted the idea of feeble observationism, only concerning the acceptance of existence. This is the idea of spontaneous behavior, according to which the considered phenomena would spontaneously converge toward rational and efficient solutions. Such an idea marks Mandeville's analysis of 'the vileness of ingredients that constitute on the whole a healthy mixture for society', due to the transformation through competitive process of private vices into public virtues. A similar idea is expressed by the Smithian notion of the invisible hand and by Hayek's celebration of spontaneous order. Max Weber expressed the substance of the interpretation above through the principle of 'diffuse rationality', according to which in the long run the behavior of society gravitates towards rational and efficient

\footnotetext{
2 True enough, Popper's Conjecturalism (according to which theories are no more than attempts to guess) rejects the equivalence between reality and rationality that both strong and feeble obervationism imply. But verification based on experiments implies the acceptance of such equivalence.

${ }^{3}$ The notion of the residual substitutes for the postulate of deductive analysis and relates to human instincts and sentiments. The notion of derivation relates to sophisms and more or less logical reasoning starting from residuals and intended to persuade oneself and other people of the appropriateness of resulting propositions.
} 
solutions. Unfortunately, such an automatic adjustment is not warranted in a world incessantly shaken by social change. What's more, we must not only consider the long run; we must consider also the medium and short run.

The above developments have allowed the observational method to be extended to all studies on factual reality, included the social one. Even the Church has abandoned her Medieval organizational vision and accepted the observational-experimental method, not only in the study of natural reality but also accepting its extension to social reality, notwithstanding the fact that the organizational vision is much more appropriate to the interpretation of such a reality.

This inappropriate generalization of the observational-experimental method also to nonrepetitive social phenomena, on the basis of the feeble observational hypothesis of the acceptance of reality, has caused growing difficulties to understanding social reality through observation, this being marked by non-repetitiveness. These difficulties strongly undermine the profitableness of the idea of automatic adjustment (by trial and error) of the social order towards systemic rationality and efficiency in the course of competitive processes; therefore undermining the observational hypothesis of acceptance of factual reality.

It may be useful to provide some important specifications of the peculiarity of social phenomena. The evolutionary motion of societies, being much more intensive of natural motion, causes higher and increasing radical uncertainty. This causes rigidities and frequent non-linearities, dependence from initial conditions (hysteresis) and sometimes chaotic behaviour. Moreover, social selection is not characterized by the inflexibility typical of natural selection, as the former is influenced by value choices, by institutional edification, normative intervention, etc. This implies the advent, in the becoming of social reality and during the procession by trial and error of social events towards the equilibrium, of a larger number of oppositions, contradictions and inefficiencies than in the becoming of natural reality. Besides, 'errors' and fluctuations concerning the social order are stimulated by the operation of passions characterizing human actions, as underlined by David Hume and Hobbes' Leviathan. These errors and inefficiencies cannot be considered and accepted as inevitable effects of the selection (toward spontaneous order) due to the struggle for survival.

Of course, human beings need competition to improve, to avoid sclerosis, corruption and decline. But it is a duty of human intelligence to reduce the errors caused by the spontaneous development of social processes. The extension to social process of the idea that the real implies rationality and reality means necessity is completely wrong. But the impossibility of such an extension must not discourage students. In fact, social reality, being an outcome of human beings, should be easier to understand than the natural world - "man can achieve the science of this", as Vico asserted many years ago.

The above aspects and considerations have stimulated ever growing objections to the dominant spontaneous hypothesis, and hence refusals and new suggestions on method. In fact, spontaneous hypotheses erase the crucial point that social systems are the work of man; such an error has caused a growing dissatisfaction towards the observational method. This has produced a wide heterodoxy on method of social studies. Economics has largely used the combination of two major methodologies: the method of abstract rationality, that is, the building of formal theories based on mathematical formalization abstracting from reality (for instance the theory of general economic equilibrium); and the Galilean method of the verification of theoretical hypotheses through observation. The unsuitability of both the approaches to meet a (social) reality built by man and hence full of innovations for a large part 
systematically stimulated by competition, and also contradicted by the other peculiarity described above, points to the need for something different. In consequence, there have grown up a variety of proposals on method centered on particular aspects, more or less relevant, of social reality, resulting in a very fragmented and deceitful heterodoxy due to its limitations and incompleteness. ${ }^{4}$ Derived from this is an analytic interpretative variety unable to allow uniform criteria of verification and comparability of achieved results, and the Feyerabendian negation of method.

The result is a social knowledge expressing irreconcilable positions and hence markedly dependent on the dialectical ability of students: in sum, a social thought deprived of science, heavily afflicted by confusion due to the increase of social change, that is, innovation and hence the non-repetitiveness of observed facts. Let us repeat that such heterodoxy on method denies the comparability of results and hence the fundamental prerequisite for the cumulative scientific character of knowledge.

To properly clarify the thematic here discussed, we need to return to when and why this great confusion arose, that is, to the total suppression of the organizational vision of the Medieval Church, notwithstanding its profitableness for the study of social reality. The central point of the question may be formulated as follows: the erroneousness of the medieval pretension to base the study and understanding of natural reality on the comprehension of the reason why God created the reality that we see, due to the inscrutability of God's will. Instead, it is an obligatory and very fecund question to wonder about (that is, attempt to consider) the reasons why man has organized society as we see. In fact, man can well understand the reasons of his work. Such a query is the most efficacious way to obtain knowledge on the social world. In this way, we eliminate the extension of the hypothesis of repetitiveness (and/or mere acceptance) postulated by the observational method and make it possible to meet the becoming of this nonrepetitive reality (it being the work of man) without accepting the senseless idea of substantially ignoring such a work through the hypothesis of spontaneous behavior, which implies that the world goes due to its intrinsic virtue toward the accomplishment of 'human progressive destiny'. In this way, we avoid being subjected to deceitful and venerated philosophical and social principles, such as the Hegelian postulate of the astuteness of universal reason and the Marxian theoretical contribution that amounts to a generic invitation to trust in the fancy of history. ${ }^{5}$

Much more concrete, convincing and fecund is the idea that the world goes where the constructive and/or disruptive action of man pushes it, without ignoring being in the name of doing as the so-called constructivists incline to do. It is necessary to put human rationality at the service of the world, against the fictitious and strongly uncertain and tormented behaviour

\footnotetext{
${ }^{4}$ In my book Methodological Misconceptions in the Social Sciences, I have considered a number of positions on the method of social thought drawn by important authors, for instance: Lakatos' idea of research programs; T. S. Kuhn's idea of paradigms; T. Lawsons' distinction between natural and social reality and the appearance of novelties. Moreover, L. von Mises and other Neo-Austrians who emphasize the role of radical uncertainty; the contributions by T. Parsons, G. Myrdal, O.E. Willimson and Douglas North; institutional and evolutionary analyses, including that of G. M. Hodgson combining the institutional and evolutionary approaches; and the methodological anarchism by P. Feyerabend.
}

${ }^{5}$ Marx's method has a strictly observational character. His idea that 'reality=necessity' hides the crucial importance of the distinction between 'necessity' and 'choice-possibility' that we shall discuss later. See A. Fusari, Springer 2016 and Routledge 2017, as well as H. Ekstedt and A. Fusari, Routledge 2010. 
that the spontaneous processes by trial and error postulates, and which, as previously seen, has induced famous students to formulate great, noisy and venerated equivocations.

\section{On some organizational and interpretative categories of social systems able to provide reliable foundations to social knowledge}

We turn now to the main point of this analysis: how to provide an organizational methodological vision for the study of human society, in order to remedy the drawbacks just analyzed. The basic content of this study on the method of social thought starts here. The building of social thought needs to couple positive and normative aspects, being and doing. It must mistrust mere observation of existence and combine observation and organization. Precisely, we have to immerse ourselves in the basic character of social reality as organized and built by man; this seems to be the most appropriate way to understand and govern its contents and becoming. It follows that the obligatory starting point of the analysis of human societies is the differentiation of basic characters of social reality that may be able (and directed) to allowing the understanding of its behavior.

First, it is necessary to identify and distinguish the factors causing non-repetitive changes of social events and hence proceed to consider, in the course of those events, the following phenomena: organizational 'necessity' imposed by reasons concerning rationality and efficiency of a social system; and 'choice-possibility' in the becoming of human societies. The above conditions respectively express the phenomena of structural organization and innovation of social systems. But it is needed, first of all, to consider the non-repetitiveness due to creativity and innovation, and hence the contents of a reality qualitatively different from the natural one.

To begin with, we have to consider and identify the conditions expressing the most peculiar aspects and contents of social reality, that is, expressing human creativity and innovation and hence the intrinsic and growing (with development) non-repetitiveness of human societies. We denominate those conditions 'ontological imperatives'. They embody necessary conditions for allowing the expression and operation of evolutionary potentialities innate in human nature. The action of these imperatives in the life of human societies, therefore the operation of human evolutionary potentialities, is not warranted. They can be suffocated by social orders adverse to their effectiveness. This will obstruct the evolution over time of those societies that would remain motionless for centuries and millennia in a substantially repetitive condition, similarly to natural reality. The action of ontological imperatives will, on the contrary, totally change such behaviour, thus causing, through the advent of the non-repetition of social events, the requirement of an approach on method completely different from the observationexperimental method of the natural sciences.

It may be useful to specify some of the most important ontological imperatives, that is, institutional forms pushing human action toward creativity and innovation and so to build new worlds. The examples of ontological imperatives that follow are aimed at reducing the abstractness of our analysis on this subject.

An important ontological imperative is represented by the division of labor, as this is an important tool for the expression of human constructional potentialities. This ontological imperative plays an important role in promoting organizational efficiency and social evolution; of course, with the condition that labor division reflects individual skills, that is, expresses the evolutionary potential inherent to human nature.

Another fundamental ontological imperative concerns the role of the individual, this being a primary source of creativity and hence of the variety of social processes. Such a role implies the 
decentralization of choice and decision processes. This imperative needs the operation of personal dignity, and a personal responsibility principle to warrant the profitableness of individual action. An ontological imperative associated with this is the reciprocity sentiment as indispensable in the promotion of social cohesion.

Another ontological imperative flanking the principle concerning autonomy, dignity and sacredness of the individual, is the principle of tolerance toward dissidents; it is indispensable in allowing a systematic confrontation between different view points, and is indispensable to the evolution of knowledge in a world populated by beings endowed with limited skills; this in turns points to the need for pluralism and social justice, which constitute therefore other important ontological imperatives necessary to promote the utilization of human creative skills, these being dispersed by chance among human beings.

The degree of propulsion of each social system depends on the presence and incisiveness of ontological imperatives. The presence or absence of these imperatives expresses the degree of openness or closeness of considered societies towards novelties.

A further fundamental classification required by the study of human societies is represented by what we denominate 'functional imperatives'. These imperatives concern organizational forms imposed, in the presence of some levels of the general conditions of development, by reasons of efficiency and the organizational rationality of social systems. As such, these imperatives are determined by the operation, over time, of human evolutionary potentialities and precisely by the corresponding ontological imperatives; therefore, they markedly differ from Talcott Parsons' functional imperatives. ${ }^{6}$

It is easy to understand that the persistence of the dynamism of human societies, that is, the acquisition of general conditions of development characterized by such a persistence, needs the institutionalization of the ontological imperatives considered above, which in this way will also become functional imperatives, that is indispensable to the existence of societies expressing persistent dynamism. This means that the following are required: the role of individual initiative and the connected principles of responsibility, of pluralism and tolerance. Some functional imperatives are not in operation today, such as the principle of social justice and the practice of power as service. They are replaced, as sources of social dynamism, by some other important functional imperatives, for instance (and as capitalism teaches us), by the central role of entrepreneurship with the connected skill and propensity to innovate, to meet in the course of development process the high level of radical uncertainty due to the nonstationary character of the economy, and to perceive and anticipate with versatility changes in course. The entrepreneurial role and the phenomenon of radical uncertainty imply a connected functional necessity of the market as information and coordination tool in the presence of high and systematic uncertainty. Also, the non-monopolistic rate of profit is a functional imperative as an indispensable measure of efficiency and the degree of success of entrepreneurial action and decisions. Our book, A new economic for modern dynamic economies (Routledge 2017), develops in detail these aspects that, together with the establishment of the economic system on the centre stage of modern dynamic societies, constitute important functional imperatives.

${ }^{6}$ T. Parsons' functional imperatives mix 'necessity' and 'choice-possibility', while our functional imperatives depend on mere exigencies of organizational rationality in the given general conditions of development. More precisely, Parsons' functional imperatives express mere functional exigencies at the most deriving from 'civilization choices' or minor value premises, independently of the level of the general conditions of development. 
These imperatives are much more than basic instruments of the work of capitalism as expressed by the almost spontaneous development of the Western world, that is, a world expressing a kind of society (capitalism) that, as we shall see, expresses a specific civilization. A modern non-capitalist social system (and civilization), however evolutionary and dynamic, cannot do without them, for reasons of efficiency and organizational rationality. In addition, the notion of power-service, the alternative to power as domination, will become a functional imperative in advanced societies. ${ }^{7}$

In capitalism, important ontological imperatives are violated, particularly those concerning justice, income distribution and service-power. But the progress of the general conditions of development will attribute also to these ontological imperatives the character of functional imperatives, in this way pushing toward the overcoming of capitalism. Those imperatives can be specified through models rich in mathematics.

The previous outline on ontological and functional imperatives makes evident the following important law of social development. With the advancement of the general conditions of development pushed by the operation, in the considered social system, of ontological imperatives, these also become functional imperatives, that is become organizational necessities of the resulting societies. In fact, societies omitting the observation of these imperatives, that is failing to be consistent with the phase of development at work, will be destroyed by internal inefficiencies and contradictions and by the competition with those societies that do satisfy those imperatives. So, functional imperatives represent some gravitational centers during processes of spontaneous development. Knowledge of them is indispensable to prevent their advent being obstructed by particular interests of dominating classes.

Many examples concerning the advent, over time, of those organizational forms can be documented. For instance, in primitive societies parental organization displays the central role of functional imperative, independently of the peculiarities and the eccentricity of the various kinds of relationship, as shown by the analyses of Levi-Strauss. The multiplications of social functions and differentiations, the development of transportations and of the dimensions of territorial groups and of exchanges causes the necessity of more sophisticated social organizations. More impersonal power forms than those typical of parental organization are born side by side with the necessity of 'command power', in the substitution or superimposition of the 'power of society' on human behavior characterizing life in primitive societies. The phenomenon of 'companions in arm' and other organizational forms expressing the first kinds of command power start to transform themselves in forms of 'state power': imperial or national states with the connected centralization of political power. The conquest by the economy of a central position in the social process has caused the advent of some functional imperatives previously discussed, both in the economies operating on markets regulated by demand-supply and in those characterized by market power. In this second case, the functional imperative concerning the 'control of effective demand' becomes operative, as directed to avoid deficiency of demand. Economies in the phase of take-off require institutions and strategies able to deactivate the development trap and, later on, the trap of dualism.

The rapid increase today of international exchanges and the advent of the 'global economy' point to the need for new economic institutions and power forms that favor both the needs of decentralization and the advent of federalism among national states. In a parallel line, the need

${ }^{7}$ We have shown that in our recent and not yet published book on 'The forms of power. Domination power and service power' 
for an extension of the forms of reciprocity as necessary to warrant social cohesion also appears. The entry onto the scene of the masses in contemporary societies increases the need to combine operational efficiency and social justice also through the separation of the firm from the conflict for income distribution, and so make the market 'a pure mechanism for imputation of costs and efficiency' (we have abundantly discussed this aspect in our two books on A new economics for modern dynamic economies and Understanding the course of social reality). The same base technologies required by new phases of development can be considered functional imperatives.

We see, therefore, that the specification of ontological and functional imperatives needs an organizational vision on method, that is, one based on the notion of the organizational rationality of social systems.

\section{Necessity and choice-possibility in the edification and functioning of human societies.}

We must now dedicate attention to a fundamental distinction implied by the organizational vision on method: what represents 'necessity' and what expresses 'choice-possibility' in the organization of social systems. ${ }^{8}$ Organizational necessities are not a matter of observation. In fact, history teaches that they can largely be ignored in practice and even strongly denied. Choice-possibility has no an observational character as it concerns choice. Yet such impossibility of observation does not imply the impossibility of understanding and treating this question.

To understand social processes, it is imperative to concentrate first of all on the organizational necessities distinguishing them. The study of historic processes, for instance, the transition from feudalism to the merchant societies of the Middle Ages, clearly shows the 'necessity', in each phase of development, of forms of power, ethical values, particular visions of the world, and their pointlessness in other situations. History teaches us that the operation of spontaneous tendencies toward existing or emerging organizational necessities has often generated great torments and, in case of failure, that social systems have been forced to go backward towards previous phases of development. It may be useful to provide some examples of organizational necessities.

The first students of capitalism were fascinated by the functioning of the economy through spontaneous processes. They considered this due to the work of the market, to which some of them attributed the character of natural law. But the market is simply an organizational necessity of modern dynamic economies that arises due to the impossibility of meeting radical uncertainty (which strongly characterizing such economies) through centralized decision making. Here we do not consider further organizational necessities as it is sufficient to recall, in this regard, the notion of functional imperatives.

Instead, we must concentrate on 'choice-possibility' that, as such, implies conflict. In this way we complete the representation of social reality, both through the consideration of long run options and their implications, and of more detailed questions. The specific character of any one social system will depend on the articulation of choice-possibility as dependent, first of all, on the advent of innovations.

\footnotetext{
8 The distinction between necessity and choice-possibility should give the heart of a science of the organization of social systems. See A. Fusari, Reformism and method of social sciences Mondoperaio 2004, $\mathrm{n}^{\circ} 1$.
} 
Some aspects of choice-possibility have long duration and substantial implications and assume the forms of civilizations. Here an important aspect of our exposition emerges: the difference between necessity and duration. Long run options, with large implications, such as those concerning civilizations, do not express organizational necessities but are a result of choiceprocesses and express the most fundamental ideological choices around which the whole social reality is structured and integrated. They may be denominated 'great options'. Examples include: the 'idea of progress', typical of the Western world: 'conformism' and 'obedience culture', typical of bureaucratic-centralized and autocratic orders. These great options (or key ideas) are the result of very long processes of elaboration and can be removed only with much gradualness, during long periods of time involving nations, ideals, behaviours, institutions, in sum the building of a new social universe in place of the existing one. As such, they constitute an important factor of continuity.

The 'civilizations' express the institutionalization of ideological and technological choices expressed by great options, with the implied organizational forms and conditionings of the natural environment. But the notion of civilization differs from that of society or social system, being less inclusive than both. In fact, it excludes functional imperatives and basic technologies, as these concern every society, for some given level of the general conditions of development; it also excludes technologic choices and innovations not yet institutionalized.

Clearly, the notions of civilization and functional imperatives, even if both concern the long run, differ in a basic character: the first expresses a choice, while the second concerns the formulation of a general principle and 'necessity'. Civilizations, as a result of choice, have a conflicting content. Differently from functional imperatives, they do not vary with the changes in the general conditions of development; they have a strong propensity to preserve themselves. Their birth marks periods of intense creativity, but their inclination to preserve themselves is a cause of sclerosis. By contrast, functional imperatives have not a conservative character since they vary with the general conditions of development and, for given general conditions of development, place people and nations under similar organizational exigencies.

The advent of new functional imperatives drives existing civilizations towards extinction and promotes new ones consistent with the new functional imperatives, hence more efficient, competitive and, in sum, more appropriate to the new conditions of development.

Evolutionary processes are pushed by innovations and choice forms. We do not consider here specific contents of innovations; their specificities cannot be explained as being a result of creative processes, which are creative phenomena the specific characters of which cannot be foreseen.

\section{Some deceits suffered by religious thought: the ethical aspect and the observational- experimental method's inauspicious seduction of Christianity}

It now becomes indispensable to consider a very delicate and involved aspect of social reality that is nevertheless condemned to heavy misunderstandings and omissions by the domination of the observational-experimental method. We refer to ethics, which expresses the most peculiar aspect of social reality and, in some sense, the true typicality of this reality as edified by man. The observational-experimental method is not suitable to formulate explanations on ethics; and it is forced to accept this as it is, that is, to consider it impossible to provide a scientific explanation. The result is the domination of the notion of 'cultural relativism', that is, the acceptance of existing ethical values as something important but impossible to explain, in sum, something which is not a scientific subject. 
In short, the observational-experimental method is unable to edify a science of ethics, an aspect of reality that is extremely important for the government of human societies. Of course, religions do not accept this kind of agnosticism on ethics, that is, the relativist assumption that all ethical values have, in principle, equal (that is zero) dignity and that, therefore, men can freely choose among them. Therefore, religions oppose to cultural relativism a substantial 'cultural absolutism', according to which ethical values would be an object of faith; and are satisfied to see that cultural relativism has as its counterpart only cultural absolutism. Unfortunately, such absolutism subjects ethical question to paralyzing oppositions, which are made particularly disturbing by the central importance of ethics in the government of human societies. Clearly, human reason is obliged to see in this condition of knowledge a great lack of scientific thought, which has caused heavy and insoluble conflicts over the course of history.

This absurdity, represented by the presumption that science is powerless in the face of ethical values, clearly shows the poverty and dangers of the observational-experimental method when referred to the analysis of social reality; it clearly appears that the government of human societies must strongly distrust such a method. However, it emerges that to go beyond this disastrous scientific impotence caused by the extension of observational (and/or abstract rationality) visions to social reality requires a change in vision, a turn towards a method appropriate to social reality as produced by man. This is the organizational vision that, as such, is suited to understand why and how man has built his social world, including its ethical content, and the best way to organize and govern it.

This is something analogous to the organizational vision of the Medieval Church that thought to explain the reason why the Creator has organized natural world in the way we see: a deceitful pretension that, as we saw, was defeated by the Galilean observational method. Unfortunately, the great success of such a method deleted the reference, even if fecund, of the organizational vision to the study and administration of human societies which, as a consequence, has known an inappropriate extension also to them of the observational and abstract-rationality methods or, as previously seen, of a growing and confused methodological pluralism, as an answer to the growing failures of the observational method in social thought.

Well, questions of ethical values indicate the road we are obliged to take to overcome such confusion. In other words, it indicates that ethics can be scientifically treated only on the basis of an organizational view, that is, one centered on the problem of the edification and administration of human societies. True enough, the ethical aspect is a fundamental passage of the organizational approach that we have defined, and a major propellant toward it. Moreover, it is the only path able to turn the ethical question, of such crucial importance in the working of any social system, from the dead-ends expressed by cultural relativism and absolutism. The notion of functional imperative plays a fundamental role in the solution of the enigma. In fact, we have seen that important functional imperatives concern ethics. For instance, value premises concerning institutional decentralization, pluralism, confrontation with different theories, individual initiative and service-power constitute organizational necessities for the existence and efficiency of modern dynamic societies. It may be useful to remember that the imperatives above play an important role in the evangelic teaching, but notwithstanding this, their central importance has been ignored. Cultural relativism and absolutism do not exhaust 
the question of ethical values. There is much more; precisely, there is what may be called 'cultural objectivism', consisting in the scientific explanation of important aspects of ethics. ${ }^{9}$

The analysis of ethical aspects obliges some considerations on the notion of utopia. In fact, such a notion intensively expresses ethical-ideological aspects. Utopia concerns choice and, as such, can clash with civilizations and cause great fractures. A fundamental propulsive role is expressed by utopias that 'anticipate' new functional imperatives and that establish ontological imperatives. These utopias strongly accelerate development processes. Christian prophecy on the role and dignity of the individual is an important example of this kind of utopia. But there is also the opposite case of utopias contrasting with ethical aspects concerning existing or future functional imperatives. These utopias operate as degenerative phenomena and the competition among social systems will obscure them, notwithstanding the forces, illusions and particular interests that operate in their favor.

The deceits suffered by religious thought on the interpretations and teachings that the administration of human societies need is not limited to the above considerations. We have seen that a great deceit suffered by the Church has been the renouncing of her ancient organizational intuition under the influence of the success achieved by the observationalexperimental method in the study of nature. This is to have not understood the usefulness of such intuition in the studies of human societies that therefore were also defeated by naturalistic observationism. Some more specific consideration on this matter may be useful.

Pope Francis' speech to the Pontifical Academy of Social Sciences condemned the endemic increase of social inequalities, of exploitation and the diffusion of the profit motive. Such a remark shows an influence of the observational method against the organizational vision that the Church should recommend in her social doctrine. In fact, the Pope's recommendation against the pursuit of profit refers to capitalist profits, that is, it is based on such factual reality. But profit cannot simply be condemned. The profit rate is an indispensable measure of the degree of success and efficiency of entrepreneurial decision-making, but capitalist profits also influence income distribution. An organizational vision on the economic system privileging justice should manage to delete capitalist profit, on the basis of what we denominate the 'principle of separation' of entrepreneurial action from the modalities of income distribution, making the market a pure mechanism of imputation and efficiency'. ${ }^{10}$ This seems to be indispensable if we are to, to use the Pope's expression, civilize the market. In addition, the Pope's observational pronunciation against the golden calf of the present time, the achievement of efficiency, deserves reservations. In fact, it seems to us that this is not the true problem. Efficiency must be pursued; if it is not, capitalism will do that in its own way. The pursuit of efficiency does not contrast with basic ethical values if it is separated, according to our 'separation principle', from income distribution. Such a separation, which we have considered at length in the referred books, will make consistent the pursuit of efficiency with social justice, thus allowing us to challenge and defeat capitalist domination.

\footnotetext{
9 In this regard, see A. Fusari: Costruire l'oggettivismo culturale; verso un'etica mondiale, in Argomenti Umani, 11/ 2006, where the ethical problem is deepened with reference to relational reality and the plurality of ethics in the global world. See also A. Fusari, Tra relativismo e oggettivismo culturale, in Argomenti Umani 5/2, 2006.

10 We have developed this aspect in our two books: A new economics for modern dynamic economies: Innovation, uncertainty, entrepreneurship (Routledge 2017), and Understanding the course of social reality: The necessity of institutional and ethical transformations of utopian flavor (Springer 2016).
} 


\section{For a theory of historic-social processes}

This essay ends with a short exposition on social processes and the interpretation of history implied by our analyses on the method of social thought.

We have considered the fundamental propulsive role on social processes of ontological imperatives, that is, ethical values and institutions expressing the evolutionary potential of man, as well as the condemnation to a stationary state of human society that results from the absence of those imperatives. Their work causes the progress of the general conditions of development of the considered social systems, thus determining the necessity of adaptation of organizational forms to the new and more advanced factual reality. It will need to introduce organizational forms congenial to the substance of the new general conditions of development, that is, organizational forms able to warrant the rationality and efficiency in the new and more advanced societies. We have denominated as functional imperatives such organizational and ethical-ideological forms that vary with the advancement of the general conditions of development. For the large part, what will happen is the gradual transformation of ontological imperatives also in functional imperatives that will make consistent the evolutionary potential of the social system with the requisite of organizational rationality and efficiency. Yet there is more. These organizational necessities are flanked by the role of choice-possibility, that is, innovative and creative human action.

Choice-possibility refers, first of all, to great options, which express the basic character of civilizations. An important character of great options is their eventual degree off openness toward ontological imperative and hence to factors causing development.

Social development is basically distinguished by the succession and intertwining of two phases that have determined the overcoming of the primitive stationary state: the phase of innovation and creative dash, which destabilizes existing social reality, and the exigency of a subsequent phase of organizational structuring and rationalization aimed at developing the implications of the innovation dash and putting the social system back in order, according to the postulate of organizational rationality, of organizational forms consistent with the structural novelties deriving from successful innovations.

A significant representation of social development can be expressed in this way: In consequence of the advancement of general conditions of development as pushed by the presence of civilizations incorporating important ontological imperatives, these will also become functional imperatives, so that their fulfillment becomes an organizational 'necessity' (that is, imposed by exigencies of organizational rationality) of resulting societies. We can see, therefore, that functional imperatives constitute important gravitational centres that display a strong and ineluctable attraction during the spontaneous processes of trial and error. This suggests the need to dedicate great attention to warrant the advent of these imperatives, thus avoiding their obstruction or delay due to misunderstandings and prejudices, for instance fed by the interests of dominating powers.

Our analysis of social process can be easily extended to the interpretation of history. Such an extension needs a notion of 'historic phase', intended as resulting from the character of the general conditions of development at work. This allows, on the basis of the previous treatment of social processes, the interpretation of the historic processes that follows: The action of ontological imperatives will determine the evolutionary behavior of social system. This will cause changes in the general conditions of development, that is, new and more advanced historic phases, which will demand the advent of new functional imperatives, that is, new and 
more advanced organizational forms able to warrant the rationality and efficiency of the new social order. In the long run, this may imply the advent of new civilizations coherent with the new functional imperatives. And so on, during the innovative and structuring processes expressing the historic course. ${ }^{11}$

In this process, creation and innovation act as engines of the whole process, while the organizational structuring that follows, over the course of social edification, to remedy the inconsistencies raised and hence to prepare the conditions that will promote a new innovative dash. A fundamental role of social thought is the distinction of 'organizational necessity' from 'choice-possibility', that is, to acknowledge both functional imperatives and great options (which characterize civilization choices), thus avoiding that these choices may be inconsistent with functional imperatives.

In some sense, historical events may be considered as laborious and prolonged institutional elaborations operating in the phase of development through which society is moving. Historic process results in a motion along subsequent phases of development, each one of them incorporates the inheritance of past conditions, opens the door to the phase that will follow and imposes some game rules to observe, thus avoiding the accentuation of torments due to trial and error process to which historic becoming would otherwise be obliged,

It may be useful to provide a brief comparison of this theory of historical processes with some others elaborated by important students.

Herbert Spencer formulated a theory of historic processes of a strictly evolutionary character, inspired by Darwin's theory of natural selection. His is a unidirectional theory of progress coming from an undefined homogeneity to a heterogeneity to which is associated a growing systemic complexity. Such evolutionary process would be pushed towards equilibrium by natural selection, with an implied elimination of conflicts, towards the harmony and general happiness. This optimistic vision is clearly contradicted by the course of universal history. This author ignores the role of creativity and of social change and development, which cause conflicts and disequilibria. Spencerian hypotheses of continuous change and a growing harmony of social reality are reciprocally inconsistent.

Hayek's theory of social process attributes a central role to unintentional events, uncertainty and learning by doing. Hayek accepts Mandeville's and Smith's teaching on the virtue of spontaneous behavior. His incapacity to distinguish necessity from choice-possibility and functional imperatives from civilizations, coupled to the great role he attributes to spontaneous processes, lead him to recommend liberal institutions. The absence of consideration of competition based on innovations impresses on the process a tendency toward equilibrium. The absence of consideration of innovative phenomena is the main cause of Hayek's great faith in spontaneous order and the major limitation of his analysis.

Spengler's interpretation of history deserves attention as emphasizing the role of irrational behaviour. He substitutes the role of intuition for that of reasoning, thus underlining the importance, in historic vicissitudes, of passion, intuition, superstition, and the role of civilizations. All this is in conflict with the interpretative role of the rationality principle. The author concentrates attention on the vicissitudes of civilizations (birth, development, death) and indicates in the parabolic evolution of these both the meaning and substance of historic becoming. These aspects of his analysis deserve attention. But the superb Spenglerian sense of 
civilizations is insufficient for the interpretation of history; moreover, it causes serious errors and misunderstandings in the matter. He does not consider the notion of ontological imperatives and the importance of the presence or absence of those imperatives in the existing civilizations.

It is important to establish that civilization is not all. Spengler ignores the notion of a social system that, as we know, includes important aspects that are absent in the notion of civilization, such as functional imperatives and non-institutionalized forms generated by innovation. The interaction between civilization and functional imperatives, implied by the distinction in historic phases, and the succession between innovative dash and structural organization (notions that, as just seen, are central aspects of the interpretation of history) are absent in Spengler's analysis. True enough, these aspects are irrelevant in the study of stationary societies that are distinguished by strong and deeply routed civilizations covering the whole social system. But these omissions become very relevant in the study of modern dynamic societies, the destiny of which does not follow the parabolic behavior of civilizations. In fact, such societies have a strong tendency to be overwhelmed by the final stage of civilizations, an overwhelming underlined by the title of Spengler's book@ The decline of the West.

A. Toynbee also sees history as a succession of civilizations. But, differently from Spengler, he develops a very extensive notion of civilization that substantially coincides with the notion of social system. This allows him to paint a superb picture of universal history, but at the cost of a weakening of his interpretative approach. He attributes a central role to creative and innovative events. His conception of 'challenge and answer' has no Darwinian content but underlines that the creativity of the answer is an essential condition for development. Unfortunately, this author neglects the obstacles to creativity that may derive from the character of civilization. The two aspects of innovative dash and organizational structuring operate, in his interpretation, in a confused mixture, as his historic periodization concerning the vicissitudes of Greek civilization and the Roman Empire show. These misunderstandings preclude the enunciation of a long run mechanism of historic-social processes, as we underlined, that is: the interaction between civilization, functional and ontological imperative and a precise distinction of development phases of universal history. Such an omission makes Toynbee's historic periodization arbitrary.

Ortega Y Gasset's interpretation of universal history attributes a crucial importance to creative phenomena and the non-repetitiveness of social events. He gives a sharp reformulation of 'challenge-answer' theory, binding it to human imagination, and emphasizes that the characters of human nature provide the dynamic principle of history, the engine of social change. His theory of crises is a coherent outcome of such a vision and his interpretation of historic process centered on the notion of human action concerns a particular kind of man, the Western one. This author's insistence on creative phenomena provides him with the material able to allow a convincing interpretation of the birth of civilizations. But his theory of crises and decay is not convincing. His insistence on the character of Western man prevents the exposition of a theory of civilization processes better argued and more general. He forgets the decisive interrelation between civilization and functional imperatives. However, Ortega's insistence on the role of the individual is important as it underlines such a fundamental ontological imperative. But Ortega does not see the great explanatory role of the distinction between necessity and choice-possibility and the notion of functional imperative. 
L. Pellicani has developed an interpretative model of historic social development quite peculiar, as a premise to an explanation of the 'genesis of capitalism'. He presents a detailed analysis of political factors that prevented the modernization of Eastern societies. In such a way, he throws light on the institutional conditions and social climate indispensable to the efflorescence of modern dynamic society. Pellicani insists on the notions of closed and open society and underlines the obstacle to human creativity etc. represented by absolute political power and by the institutional centralization typical of Eastern societies. This interpretation is illuminating but insufficient. It cannot be referred to: the history of pre-Roman Mediterranean area; the Roman Republic and Roman Empire from Augustus to the Antonines; the history of India and the Islamic world, where political disintegration long prevailed over centralization; and societies stagnating in a primitive stage. The absence of the distinction between 'necessity' and 'choice-possibility' occludes the fact that a dynamic society can even be built on not properly capitalist foundations. Moreover, the absence of the notions of ontological and functional imperatives ignores these important constitutive elements of a general theory of historic-social process.

\section{CONCLUSIVE SYNTHESIS}

To conclude, social science must be based on an organizational vision of human societies. More precisely, it must start with the definition of general principles and the classification of the considered reality according to some important interpretative and organizational categories. Moreover, it must define great options that give rise to civilization forms. In a parallel line, the operation of choice-possibility will determine, on the wave of successful innovations and side by side with the great options on civilization forms, the advent of particular and specific aspects of the studied reality. As is evident, all this has nothing to do with the observationalexperimental method of the natural sciences, nor to the method of abstract rationality typical of logic-formal and mathematical sciences (or a combination of both methods, as frequently found in economics). We have centered the analysis, interpretation and administration of social reality on the distinction of its contents and character, which follows:

First, ontological imperatives that express institutional and ethical-ideological forms, the presence (or absence) of which determine the working (or suffocation) of evolutionary potentialities innate in human nature, and therefore causes development process, or vice versa, maintain in incubation human societies for centuries and millennia in a stationary condition.

Second, functional imperatives, expressing organizational forms of human societies imposed, for reasons of organizational rationality and efficiency, by the content of the general conditions of development that have arisen in the course of the evolutionary processes and their changes over time, due to the stimulation eventually played by ontological imperatives.

Third,_civilization forms expressing the sedimentation through choice processes of great and durable ethical-ideological options.

Fourth, particular and contingent aspects of social systems as generated by human creativity and the connected successful innovations.

Therefore, we see the interaction, in the organization of human societies, side by side with the aspect of 'necessity' concerning exigencies of organizational rationality and efficiency, the aspect of 'choice-possibility' expressed by more particular aspects of the social system, while ontological imperatives act as the engine of the whole process. The understanding, organization and administration of human societies should be centered on the accurate analysis of these four aspects and their interactions. The study of the reality analyzed through 
the organizational method that we have proposed is a very different thing with respect to the observation and acceptation of existing reality and the consequent definition of laws of motion, as the observational-experimental method gives us, which can only be referred to a repetitive or quasi-repetitive reality.

It is evident that the observational method, which is at the base of the discovery of the laws of motion and is intended to make easy man's interaction with the concerned reality, is based on the acceptance of existing as expressed by the spontaneous behaviour of observed reality. This ignores the very distinctive trait of such a reality, that is, the circumstance that it is man's construction, who is therefore not condemned to submit to it. The study of human societies does not concern only being, the existing, but flanks also doing as resulting from men's organizational and constructive capacities and action. Therefore, it is largely concerned with becoming. The four interpretative categories expressing the organizational method that we have defined act as a guide to forms of edification of human societies and of understanding of their substance. This gives much more understanding than simple trust in the virtue of mere observation of existence, of what happened, and its acceptance. The organizational method that we propose places the human action at the centre stage of the analysis. Its operation tells us where we are going and where we can go.

\section{References}

Boudon, R. (2005). The poverty of relativism. Oxford: Bardwell

Di Nuoscio, V. (2006). Il mestiere dello scienziato sociale. Napoli: Liguori Editore

Ekstedt, H. e Fusari A. (2010). Economic theory and social change. Problems and revisions. London/New York: Routledge

Feyerabend, P. K. (1975). Against method Milano: Feltrinelli

Fusari, A. (2014). Methodological misconceptions in the social sciences. Rethinking social thought and social processes. Dordrecht, Heidelberg, New York, London: Springer

Fusari, A. (2016). Understanding the course of social reality. The necessity of institutional and ethical transformations of utopian flavour. Springer, Switzerland

Fusari, A. (2017). A new economics for modern dynamic economies. Innovation, uncertainty and entrepreneurship.. New York and Abingdon Oxon: Routledge

Galilei, G. (2001) Sidereus nuncius. Letteratura Universale/ Esperia

Hayek, F. A. (1949). Individualism and economic order. London: Routledge \& Kegan Paul

Hayek, F. A. (1999). The fatal conceit. The errors of socialism. Chicago: University of Chicago Press

Hegel, G. W. (1987). Enciclopedia delle scienze filosofiche in compendio (A. Negri Ed), Bari: Laterza

Hermann, A.(2015). The sistemic nature of the economic crisis. The perspecives of heterodox economics and psychoanalysis. Routledge, Abingdon and New York

Hobbes, T. (2006). Leviatan. Roma: Editori Riuniti

Hodgson, G. M. (1988). Evolution and institutions. Chelthenam/Northampton: Edward Elgar

Hume, D. (1997). Un'inchiesta sui principi della morale. Laterza: Bari e Roma

Kant, I (1982). The critique of pure reason. The critique of practical reason. The critique of jujudgements. William Benton Publisher/ Enciclopedia Britannica

Kuhn, T. (1978). LThe structure of scientific revolutions. Torino: Einaudi

Lakatos, I. (1984) 'The history of science and its rational reconstruction'. In, I. Lakatos \& A. Musgrave (Eds.). Citicism and growth of knowlwdge. Milano: Feltrinelli

Lawson, T. (2006). 'The nature of heterodox economics', Cambridge Journal of Economics, 30. 483-505

Levi-Strauss, C. (1968). La vie familiale et sociale des Indiens Nambikwara. Paris : Societé des Americanistes 
Mandeville, B. (2000). The fable of bees. Bari: Laterza

Myrdal, G. (1966). Il valore nella teoria sociale. Torino: Einaudi

North, D. C. (1993). Institutions, institutional change and economic performance. Cambridge: Cambridge University Press

Pareto, V. (1960). Oeuvres complete (publié sous la direction de G. Basino). Genève: Librairie Droz

Parsons, T. (1987). The structure of social action. Bologna: Il Mulino

Pellicani, L. L. (2006 ). La genesi del capitalismo e l'origine della modernità. Cosenza: Marco Editore

Pera, M. (1982). Apologia del metodo. Bari: Laterza

Popper, K. R. (1976). The poverty of historicism. London/Hanley: Routledge \& Kegan Paul

Smith, A. (1995). La teoria dei sentimenti morali. Milano: Rizzoli

Spencer, H. (1896), The study of sociology. New York: D. Appleton and Company

Weber, M. (1974). The method of the social-historical sciences, Torino: Einaudi

Williamson, O. E. (1985). The economic institutions of capitalism. New York: Free Press 